\begin{tabular}{|c|l|}
\hline Title & Dynamic Response of aChevron Concentrically Braced Frame \\
\hline Author(s) & Okazaki, Taichiro; Lignos, Dimitrios G.; Hikino, Tsuyoshi; Kajiwara, Koichi \\
\hline Citation & $\begin{array}{l}\text { Journal of Structural Engineering- A SCE, 139(4), 515-525 } \\
\text { https:/doi.org/10.1061/A SCE)ST.1943-541X.0000679 }\end{array}$ \\
\hline Issue Date & 2013-04 \\
\hline Doc URL & http://hdl.handle.net/2115/52750 \\
\hline Type & article (author version) \\
\hline File Information & STENG-1913-1.pdf \\
\hline
\end{tabular}

Instructions for use 


\section{Dynamic Response of a Chevron Concentrically Braced Frame}

Taichiro Okazaki, A.M.ASCE ${ }^{1}$; Dimitrios G. Lignos, A.M.ASCE ${ }^{2}$; Tsuyoshi Hikino ${ }^{3}$; and Koichi Kajiwara ${ }^{4}$

4 Abstract: Large-scale shake table tests were conducted at E-Defense, Japan, to examine the dynamic response of a steel concentrically braced frame. The specimen was a single-bay, singlestory frame with a pair of square-HSS braces placed in a chevron arrangement. The gusset plates connecting the brace to the framing elements were provided with an elliptic fold line to

8 accommodate out-of-plane rotation of the brace in compression. The specimen was subjected

9 repeatedly to a unidirectional ground motion with increasing magnitude until the braces buckled

10 and eventually fractured. The bracing connections performed as intended; the gusset plates

11 folded out-of-plane and no crack was observed in the gusset plate or in the critical welds.

12 Consequently, the test results demonstrated excellent performance of the bracing connections.

13 Elastic deformation of the beam prevented the braces from developing their full tensile strength.

14 Yielding in the middle of the beam, which was predicted by monotonic loading analysis, did not

15 occur. The specimen response was reproduced by a numerical model using fiber elements. This

16 model was able to predict the occurrence of brace buckling and fracture and thereby, accurately

17 trace the dynamic behavior of the frame.

18 Subject Headings: Shake table tests; Steel frames; Seismic design; Bracing; Connections; Nonlinear analysis.

\footnotetext{
${ }^{1}$ Associate Professor, Graduate School of Engineering, Hokkaido University, Sapporo, Hokkaido 060-8628, Japan. (formerly researcher at National Research Institute for Earth Science and Disaster Prevention) . E-mail: tokazaki@eng.hokudai.ac.jp

${ }^{2}$ Assistant Professor, Department of Civil and Applied Mechanics, McGill University, Montreal, Quebec H3A 2K6, Canada. E-mail: dimitrios.lignos@mcgill.ca

${ }^{3}$ Manager, Nippon Steel Engineering Co. Ltd., Shinagawa, Tokyo 141-8604, Japan. (formerly researcher at National Research Institute for Earth Science and Disaster Prevention). E-mail: hikino.tsuyoshi@nsc-eng.co.jp

${ }^{4}$ Director of Hyogo Earthquake Engineering Center (E-Defense), National Research Institute for Earth Science and Disaster Prevention, Miki, Hyogo 673-0515, Japan. E-mail: kaji@ bosai.go.jp
} 
Concentrically-braced frames (CBFs) are a widely used structural system to achieve the

3 lateral stiffness and strength required by modern seismic design provisions. The design rules in

4 the AISC Seismic Provisions for Structural Steel Buildings (AISC 2005a) are based on extensive

5 research conducted since the 1970's (e.g., Popov et al. 1976; Astaneh-Asl et al. 1986; Nakashima

6 and Wakabayashi 1993; Tremblay 2001; Tremblay 2002), which suggest that the seismic

7 performance of CBFs is controlled by the width-to-thickness ratio and slenderness of the braces.

8 Recent tests by Uriz (2005), Lehman et al. (2008), and Roeder and Lehman (2009) indicate that

9 secondary bending in the framing members can significantly affect bracing connections. The

10 current provisions can lead to large and thick gusset plates, which restrain the framing members

11 and thereby draw significant stresses to the gusset plate welds. Laboratory tests indicate that

12 CBFs with such bracing connections can fail in the gusset plates or at the welds before the

13 deformation capacity of the braces are exploited. Based on such observations, Lehman et al.

14 (2008) and Roeder et al. (2011) developed a design procedure that promotes compact and thin

15 gusset plates, and thereby leads to increased drift capacity of CBFs.

CBFs with braces arranged in a chevron (or an inverted-V) pattern is frequently used

17 because of their architectural advantages. Chevron CBFs require special considerations that are

18 not required for other CBF configurations. Early experiments by Shibata and Wakabayashi

19 (1963), Yamanouchi et al. (1989), and Fukuta et al. (1989) suggest that the seismic behavior of

20 chevron CBFs is significantly affected by force unbalance between the tension brace and buckled

21 compression brace. If the beam intersecting the braces is unable to sustain this downward force,

22 a plastic hinge will form in the beam before the tension brace can develop its yield strength.

23 Studies by Khatib et al. (1988) and Tremblay and Robert (2001) warn that this mechanism is 
1 undesirable for CBFs. Consequently, the 2005 AISC Seismic Provisions require the beams in

2 chevron CBFs to be designed for the condition where the tension brace is fully yielded and the

3 compression brace has buckled and lost much of its strength. In addition, braces in chevron

4 CBFs are expected to develop inelastic deformation primarily in contraction. For example, a

5 large-scale test by Uriz (2005) suggests that, even if the beam is designed for the force unbalance

6 per the 2005AISC Seismic Provisions, the elastic deflection caused by the force unbalance can be

7 large enough to prevent tensile yielding of the brace.

8 This paper describes a shake table test program of a large-scale chevron CBF specimen.

9 The objective of the program was to confirm the available knowledge of CBFs including cyclic

10 brace behavior, the effect of framing action on bracing connections, and characteristics of

11 chevron systems, which is based mostly on static loading tests. The specimen is one of few large-

12 scale chevron CBFs tested to date and the only large-scale CBF tested dynamically. In addition,

13 the test results are used to demonstrate that numerical models can be calibrated to simulate

14 inelastic buckling and fracture initiation due to low cycle fatigue.

\section{Test Plan}

16 A single story, single span, chevron CBF specimen was subjected to a series of strong

17 earthquake ground motions. The tests were conducted at E-Defense; a three-dimensional, large-

18 scale earthquake testing facility operated by the National Research Institute for Earth Science

19 and Disaster Prevention of Japan. 
Fig. 1 shows an elevation of the CBF specimen. The 4.15-m span and 2.25-m height

2 correspond to $70 \%$-scale of typical building structures. The specimen may represent the bottom

3 story of a 3 to 5 -story building in Japan. The frame comprised a built-up wide-flange beam $(d=$

$\left.4300, b_{f}=150, t_{w}=6.5, t_{f}=9 \mathrm{~mm}\right)$, two cold-formed square-HSS columns $(d=b=200, t=9$

$5 \mathrm{~mm})$, and a pair of square-HSS braces $(d=b=75, t=3.2 \mathrm{~mm})$. The braces connected to the

6 beam-to-column joints through 4.5-mm gusset plates. The standard through-diaphragm detail

7 (Nakashima et al. 1998) was used to achieve rigid beam-to-column connections.

For each material comprising the specimen, Table 1 lists the material designation, either

9 by the Japanese Industry Standards (JIS) or by the Japan Iron and Steel Federation. The specified

10 minimum yield strength is $245,235,295$, and $245 \mathrm{MPa}$, respectively, for STKR400, SN400,

11 BCR295, and SS400 steel. Both HSS materials, BCR295 and STKR400, were formed from a flat

12 plate and completed with one longitudinal seam weld. While BCR295 steel is commonly used

13 for columns subjected to biaxial bending, STKR400 steel is a typical material for bracing. The

14 STKR400 standard lacks the minimum Charpy V-Notch toughness, chemical control for

15 weldability, and yield-to-tensile strength ratio requirements, which are specified for BCR295.

16 Table 1 indicates that the measured yield strength for the beam and columns and HSS braces was

$1750 \%$ stronger than their respective specified minimum value. Similarly large measured-to-

18 nominal yield strength ratios have been reported by Lehman et al. (2008), Roeder et al. (2011),

19 and Fell et al. (2009) for ASTM A500 material. Interestingly, the measured yield strength for the

20 gusset plate, $204 \mathrm{MPa}$, did not meet the specified minimum value of $245 \mathrm{MPa}$.

The bracing connections shown in Fig. 2 did not represent typical Japanese design. The

22 three gusset plates were designed according to the balanced design proposed by Lehman et al.

23 (2008); by adopting an elliptic clearance distance of eight times the thickness of the gusset plate, 
1 the unsupported segment between the brace and the beam and column flanges was shortened,

2 thereby enabling relatively thin, compact gusset plates. The gusset plate at the top end of the

3 braces, connecting the braces to the beam at its mid-span, was provided with a pair of vertical

4 stiffener plates. As indicated in Fig. 2, each end of the brace was welded to a gusset plate along

5 the slotted edges of the brace and clipped portion of the gusset plate. Net section reinforcement is

6 not needed for this detail. The welds between the brace and gusset plate and between the gusset

7 plate and beam and column flanges were placed with the specimen standing in the upright

8 position, and made by a shielded metal arc welding process using a 3.2-mm diameter JIS Z 3211

9 electrode. The welds were sized to develop the full strength of the base material.

Prior to the tests described in this paper, the beam and columns of the specimen were

11 used for a different test, where a pair of dampers was placed in the same chevron arrangement

12 and where the frame developed drifts near but smaller than $0.01 \mathrm{rad}$. After this prior test was

13 completed, the dampers were removed, 16-mm gusset plates were removed by arc gouging and

14 grinding, and the smaller 4.5-mm gusset plates shown in Fig. 2 were welded over the removed

15 gusset plates. Because the frame was designed to remain elastic for drifts below $0.01 \mathrm{rad}$.,

16 minimum damage had occurred in the reused beam and columns. However, because the old

17 gusset plates and fillet welds could not be ground flush to the base material, the new gusset

18 plates were welded over $30-\mathrm{mm}$ wide and 5 to $10-\mathrm{mm}$ thick leftover material. Consequently,

19 where the gusset plate was welded to a beam or column, the clearance distance for elliptic

20 folding of the gusset plate was reduced by up to twice the plate thickness.

The columns were rigidly connected to heavy base beams, which, in turn, were rigidly

22 connected to the shake table. At the top side of the specimen, each end of the beam was 
1 connected to the test-bed system described later. The specimen was laterally braced along the

2 columns and beam at discrete locations indicated in Fig. 1 by " $x$ " marks.

\section{Compliance to Code Requirements}

$4 \quad$ The square-HSS braces had a width-to-thickness ratio of $b / t=20.4$ and member

5 slenderness ratio of $K L / r=82.5$, where $K$ is the effective length factor taken equal to unity, and

6 the member length $L$ is measured between the elliptic fold lines. The $b / t$ ratio slightly violated

7 the seismically compact limit of $0.64\left(E / F_{y}\right)^{1 / 2}=18.5$, while the $K L / r$ ratio was within the limit of

$84.0\left(E / F_{y}\right)^{1 / 2}=116$ specified in the 2005 AISC Seismic Provisions to develop meaningful

9 compressive strength. These limiting values are computed based on the specified minimum yield

10 strength $F_{y}=245 \mathrm{MPa}$. The nominal compressive strength, $P_{c r}$, based on the AISC Specification

11 for Structural Steel Buildings (AISC 2005b) and the specified minimum yield strength, $F_{y}=245$

$12 \mathrm{MPa}$, was $134 \mathrm{kN}$, while the strength based on the measured strength, $F_{y}=383 \mathrm{MPa}$, was 213

$13 \mathrm{kN}$. The tensile yield strength, $P_{y}$, was $342 \mathrm{kN}$ based on $F_{y}=245$ and $342 \mathrm{kN}$ based on $F_{y}=383$.

14 The bracing connection shown in Fig. 2 was designed to develop the required tensile and

15 compressive strength of the HSS braces using the procedure by Roeder et al. (2011). While

16 Roeder et al. (2011) suggests selectively relaxing the resistance factors in the AISC Specification,

17 the designs shown in Fig. 2 fully meet the 2005 AISC Specification requirements. However,

18 based on the measured yield strength values shown in Table 1, the tensile yield strength of the

19 brace was nearly $10 \%$ larger than the yield strength of the Whitmore section of the gusset plates.

The 2005 AISC Seismic Provisions and Japanese recommendations (AIJ 2002) require the

21 beams in chevron special-CBFs to be designed for the force unbalance between the tension and

22 compression braces. Because the beam in the specimen is part of a rigid frame, the available 
1 strength of the beam to carry mid-span load is a function of the moment distribution produced by

2 moment-frame action. Fig. 3(a) shows a static pushover response obtained from the modeling

3 procedure described later and where gravity load is neglected. The same figure shows the story

4 shear developed in the columns by moment frame action. Fig. 3(b) plots the axial force in the

5 two braces as the story drift increased, along with key strength values specified in the 2005 AISC

6 Seismic Provisions. Prior to buckling of the compression brace, the braces account for $84 \%$ of

7 the frame strength. This ratio reduces to $73 \%$ after the compression brace buckles (Stage A

8 indicated in Fig. 3(a)) and to 54\% when the tensioned brace yields (Stage B). The compressed

9 brace buckles at a story drift ratio of 0.0022 rad., the tension brace yields at 0.0095 rad., and at

100.01 rad., a plastic hinge forms at the end of the rigid offset near the center of the beam (Stage C).

11 The force in the compressed brace reduces to below $0.3 P_{c r}$, which is the strength used to evaluate

12 the beam mid-span load in chevron CBFs. Even after a beam mechanism is formed, the frame

13 strength continues to increase. It is cautioned that deterioration of beam strength at the beam-to-

14 column connection is not modeled, and because gravity load is not accounted for, the model is

15 not affected by P-Delta effects.

\section{Test Bed}

The specimens were subjected to ground shaking at the E-Defense facility using the "test

18 bed" system developed by Takeuchi et al. (2008). The test beds are multi-purpose devices that

19 supply horizontal mass to the specimen while adding minimal lateral force resistance. As shown

20 in Fig. 4, a pair of test beds was used for this program, one at each side of the specimen. The

21 figure shows a three-dimensional view of the test setup with the test bed on the left side partly

22 transparent. At the base, the test bed was connected to the shake table through a set of linear

23 bearings which produced minimal friction for motion in the loading plane, and which restrained 
1 out-of-plane and vertical motion. The dynamic friction coefficient was evaluated as 0.0033 by

2 Takeuchi et al. (2008). At the top, the test bed was connected to each end of the specimen, with a

3 load cell placed in the load path. The two test beds and additional test rigs supplied a combined

4 69.4-ton mass to the specimen. The test bed was also used to anchor the out-of-plane bracing

5 indicated in Fig. 1. The test-bed system has previously been used in a similar fashion for two

6 experimental programs (Takeuchi et al. 2008; Ma et al. 2010).

\section{$7 \quad$ Test Procedure}

The scaling rules for the shake table test are summarized in Table 2 , where $\lambda$ indicates

9 the scaling factor for length. In this case, $\lambda=0.7$. Time and stress were not scaled in the test.

The East-West component of the JR Takatori motion (Nakamura et al. 1996) was

11 introduced in the direction parallel to the loading plane. The JR Takatori motion is a strong

12 motion record from the 1995 Kobe earthquake, measured immediately adjacent to the fault. The

13 EW component is characterized by a peak acceleration of $6.6 \mathrm{~m} / \mathrm{s}^{2}$ and strong velocity pulses.

14 Fig. 5(a) shows the acceleration history of the motion while Fig. 5(b) shows the response

15 acceleration spectrum obtained for a damping ratio of $\zeta=0.02$. The shake table tests were

16 conducted by introducing the Takatori EW motion seven times, with target amplification level

17 increasing from 10, 12, 14, 28, 28 (second time), to 42, and finally, 70\%. Fig. 5(b) also shows

18 the acceleration response spectra constructed from the measured table motion and for $\zeta=0.02$.

19 The targeted motion was achieved over a wide range of periods between 0.1 and 3 seconds,

20 although the $70 \%$ motion exceeded the target in the short period range between 0.1 and $0.5 \mathrm{sec}$. 
The load cells mentioned above were used to evaluate the story shear force. Displacement

2 transducers were used to monitor story drift and out-of-plane deformation of the beam and braces.

3 As shown in Fig. 6(a), strain gauges were placed at selected sections of the beam and columns.

4 The section forces estimated from strain gauge readings were combined with the equilibrium

5 conditions indicated in Fig. 6(b) to compute the axial force in the braces. Elongation of the brace

6 was measured from the change in length of the HSS member. Data was collected at a rate of

$7 \quad 1,000 \mathrm{~Hz}$. All data was passed through a low-pass filter to eliminate frequency content above 50

$8 \mathrm{~Hz}$.

9 Test Results

Frame Behavior

Based on unidirectional white noise excitation, the natural vibration period was

12 determined as $0.21 \mathrm{sec}$, which is equivalent to that of a single or two story building.

Fig. 7 shows the story shear versus story drift response measured for the three tests using

14 the 28,42 , and $70 \%$ motions. The figure indicates that the structure responded linearly during the

$1528 \%$ motion, but some nonlinearity occurred during the $42 \%$ motion. The response from the $70 \%$

16 motion plotted in Fig. 7(c) suggests that the system was affected by buckling and yielding of the

17 braces during two and one-half drift cycles of -0.015 to $+0.01 \mathrm{rad}$. The circles and triangles in

18 the figure correspond to the time instants when key phenomena were observed in the East and

19 West braces, respectively. The numbers 1 to 4 in Fig. 7(c) correlate with buckling and fracture of

20 the East brace indicated in later figures. The braces buckled and fractured within three negative

21 to positive drift excursions between -0.015 and $0.01 \mathrm{rad}$. Each occurrence of brace buckling 
1 caused a reduction in stiffness and drop in story shear, although the frame was able to regain

2 strength as the drift increased further. Near the instant when the East brace fractured at stage 4,

3 the West brace started to fracture under large contraction. The response after stage 4 is indicated

4 by a dotted line. After both braces fractured, the specimen acted as a moment resisting frame,

5 developing large deformation between -0.018 and +0.028 rad. without any strength loss. Fig.

67 (c) clearly indicates the reduction in stiffness after the braced frame reduced to a moment

7 resisting frame. At the end of the $70 \%$ motion, a residual drift of +0.007 rad. remained.

8 The largest story shear developed by the specimen was +635 and $-690 \mathrm{kN}$ in the positive

9 and negative direction, respectively. The shear strength was somewhat larger than the estimation

10 of the pushover analysis, which, as shown in Fig. 3, developed a story shear of $634 \mathrm{kN}$ at a story

11 drift of 0.02 rad. The largest story shear developed after stage 4, during which the specimen

12 acted as a moment resisting frame, was +515 and $-550 \mathrm{kN}$ in the positive and negative direction,

13 respectively. Therefore, for this specimen, the strength of the underlying moment resisting frame

14 was $80 \%$ of the maximum strength provided by the two braces.

15 After the test was completed, flaking of white wash indicated that the column had yielded

16 near the bases, although no residual deformation of the column was visible. Similarly, the white

17 wash indicated that no yielding occurred in the beam near the brace-to-beam connections.

\section{Brace Performance}

Fig. 8 shows the axial force (tension taken as positive) versus elongation relationship

20 measured from the East brace for the 28, 42, and 70\% motions. Fig. 9 shows the rotation of the

21 top and bottom ends of the East brace measured from the same motions. The response of the

22 West brace was similar to that of the East brace. In Figs. 8 and 9, the horizontal lines indicate the 
1 tensile yield strength $P_{y}$ and compressive strength $P_{c r}$ of the brace member computed based on

2 the measured yield strength and a slenderness ratio of $K L / r=82.5$.

During the 28\% motion, the braces exceeded the estimated buckling load, and Fig. 9(a)

4 indicates small out-of-plane deformation that followed brace buckling. However, the occurrence

5 of buckling is not obvious from the axial response in Fig. 8(a). At the end of the $28 \%$ motion, a

6 residual out-of-plane displacement of $6 \mathrm{~mm}$, not accounting for initial imperfection, was

7 measured in the middle of the brace. Therefore, the braces had an out-of-straightness of 1/400

8 before being subjected to the $42 \%$ motion. During the $42 \%$ motion shown in Fig. 8 (b), the braces

9 buckled under a compression close to the estimated buckling load. After occurrence of the first

10 buckling, the compressive strength of the brace reduced. It is noted that although the specimen

11 developed similar drifts in both loading directions, the braces developed larger contraction than

12 extension, and the braces did not develop their yield strength in tension. At the end of the $42 \%$

13 motion, a residual out-of-plane displacement of $17 \mathrm{~mm}$ was measured in the middle of the East

14 brace, which corresponds to an out-of-straightness of 1/133.

15 During the $70 \%$ motion, as the story drift ratio exceeded 0.01 rad., the beam yielded near

16 the connections to the column face where some of the strain gauges were placed. Beyond this

17 stage, the brace forces were estimated using a reduced number of strain gauges, and therefore,

18 the brace forces were not estimated as accurately as in the smaller motions. Nonetheless, Fig. 8

19 clearly illustrates the key characteristics of buckling brace behavior. During the first major

20 contraction, the East brace buckled at a smaller force than the maximum compression reached

21 during the 28 and $42 \%$ motions (stage 1 indicated in Fig. 8(c)). However, after experiencing

22 tension, presumably because the out-of-straightness was corrected, the brace recovered its

23 compressive strength in the next contraction (stage 2). As the brace continued to contract, its 
1 compressive strength reduced substantially. The buckling strength in the third contraction (stage

2 3) was reduced from that in the second contraction. During the third major extension, the brace

3 fractured near the middle and separated into two parts (stage 4). The West brace behaved

4 similarly. Video footages indicate that fracture of the West brace initiated immediately after

5 stage 4, when the East brace fractured, and as the West brace was contracting. Fracture of the

6 West brace occurred gradually over three subsequent extension cycles rather than

7 instantaneously as in the East brace. Fig. 10(a) shows a photograph taken after the $70 \%$ motion

8 with the fractured West brace on the near side and fractured East brace on the far side. Both

9 braces fractured near mid-length of the member. Indication of local buckling and ductile tearing

10 was more evident in the West brace, which underwent gradual fracture, than in the East brace

11 which fractured instantaneously.

12 As seen in Fig. 8(c), the braces deformed more substantially in contraction than in

13 extension, and did not develop their tensile yield strength. The reason of this behavior is

14 explained in Fig. 11, which compares the history of extension of the East and West braces and

15 vertical displacement measured at the middle of the beam. The beam displaced downwards as

16 much as $15 \mathrm{~mm}$ as one of the two braces contracted and the other extended to produce force

17 unbalance. The figure indicates how the vertical displacement added to brace contraction and

18 reduced brace extension. After the East brace failed in tension (stage 4 in Fig. 8(c)) and the West

19 brace began to fracture, the beam was no longer subjected to substantial downward forces.

20 Contrary to the prediction by monotonic loading analysis, the force unbalance between

21 the tension and compression braces did not cause plastic hinge formation in the beam.

22 Nonetheless, the force unbalance influenced the behavior of the braces by deforming the beam to

23 increase contraction and limit elongation of the brace. 


\section{Bracing Connection}

Fig. 9 shows how the top and bottom ends of the East brace rotated in opposite directions

3 as the brace deformed out-of-plane. The symmetric hysteresis indicates that the top and bottom

4 bracing connections performed equally well. The ends rotated $0.03 \mathrm{rad}$. during the $28 \%$ motion

5 and 0.08 rad. during the $42 \%$ motion. The ends rotated by as much as 0.18 rad. during the $70 \%$

6 motion as the brace underwent large out-of-plane deformation. The photographs in Figs. 10(b)

7 and (c) show that the gusset plates, either at the column base or at the mid-span of the beam,

8 folded nicely along the elliptic clearance to accommodate brace-end rotation in compression. No

9 discernable damage was observed in the gusset plates, the brace ends, or in the critical welds,

10 suggesting that the performance of the bracing connections was excellent. However, while the

11 bracing connections achieved all the design goals for braces in compression, it is suspected that

12 the connections were not subjected to the most severe conditions expected for braces in tension.

13 It is also noted that the connections were not subjected to very severe secondary bending effects.

14 In other words, had the braces exhibited longer fatigue life as expected for sections with smaller

$15 \mathrm{~b} / \mathrm{t}$ ratios, the frame would have developed larger drifts and thereby imposed larger secondary

16 bending effects on the connections.

\section{Numerical Simulation}

\section{Modeling}

Fig. 12(a) shows the numerical model constructed in the OpenSees simulation platform

20 (McKenna 1997). The model included panel zones modeled according to Gupta and Krawinkler

21 (1999) and a 300-mm-long rigid segment in the middle of the beam. The test-bed system was 
1 modeled by connecting each end of the beam to a leaning column that support half of the test-

2 bed mass. Nonlinear geometry was considered with corotational transformation. The members

3 were modeled with a displacement-based fiber element that uses the Gauss-Lobatto quadrature

4 rule. Five integration points were used along their lengths including the two placed at the ends. A

$516 \times 4$ mesh was used for the flange and web of the beam and columns and a $10 \times 4$ mesh was used

6 for each wall of the braces. Material nonlinearity was modeled using the Giuffre-Menegotto-

7 Pinto model with isotropic strain hardening and the measured material properties listed in Table

8 1. Three-percent mass proportional damping was assumed at the first vibration period of the

9 numerical model $(0.20 \mathrm{sec})$ to represent friction in the test bed.

The braces were modeled using a technique similar to the technique developed by Uriz et

11 al. (2008) and described in NIST (2011a). Each brace was split into two fiber elements and

12 provided with an initial imperfection equal to $0.1 \%$ of the brace length. The gusset plates were

13 modeled by a fiber element with a length equal to twice the gusset plate thickness and with two

14 integration points. Fracture in the critical section was considered by tracking the strain history in

15 each fiber and assigning zero stiffness to any fiber that exceed the low-cycle fatigue limit defined

16 by a rain-flow-count rule. The low-cycle fatigue limit was calibrated against quasi-static tests on

17 square-HSS braces by Fell et al. (2009) and Black et al. (1980) that had similar geometric

18 properties $\left(L / r_{y}=80, b / t=16\right)$ as the braces in the shake table tests $\left(L / r_{y}=82.5, b / t=20.4\right)$. Fig.

1913 shows an example where the calibrated brace model captured the buckling, yielding, post

20 buckling hysteresis, and fracture observed in a cyclic loading test by Fell et al.

\section{Simulated versus Experimental Results}


The measured motions of the shake table were applied to the numerical models in

2 sequential order to consider the cumulative damage effects on the nonlinear response from phase

3 to phase. Fig. 14 compares the simulated versus experimental hysteresis of the East brace for the

442 and $70 \%$ motions. The figure shows that the simulation traced the experimental response

5 fairly accurately for the $42 \%$ motion, including buckling and post-buckling response, although

6 larger tensile force was developed in simulation. For the $70 \%$ motion, the simulation did not see

7 substantial recovery of compression strength after undergoing tension, which was observed in

8 the experiment. The simulated brace fractured before completing the second major tension

9 excursion, while fracture in the experiment occurred during the third major tension excursion. As

10 described above, the fracture limit in the numerical model was calibrated against available test

11 data on braces similar to the braces in the shake table specimen. While the timing of fracture

12 could be matched by adjusting the fracture limit, the difference in timing of fracture seen in Fig.

13 14(c) indicates the difficulty of predicting fracture based on a priori information, and also

14 indicates the sensitivity of how the fracture model affects the simulated behavior of braces.

Fig. 14 shows the story shear versus story drift response for the 42 and $70 \%$ motions. The

16 figure shows that the simulation traced the experimental response fairly accurately for both

17 motions. The discrepancy between experimental and simulated response for the $70 \%$ motion is

18 primarily due to the difference in timing of brace fracture. As in the experimental response, the

19 simulation acted as a moment resisting frame after both braces fractured. As in the experimental

20 response, the simulation did not form a plastic hinge in the beam. This observation is contrary to

21 the prediction from the monotonic loading response shown in Fig. 3, and which was obtained

22 from the same model. 


\section{Design Implications}

\section{Loading Rate}

The peak loading rate of the braces was $30,60,120$, and $500 \mathrm{~mm} / \mathrm{s}$, respectively for the

$414,28,42$, and $70 \%$ motions. The peak strain rate, obtained by dividing the loading rate by the 5 brace length of $2,300 \mathrm{~mm}$, was $0.015,0.03,0.06$, and 0.2 per second, respectively, for the four

6 motions. Fell et al. (2009) compared a dynamically loaded HSS brace specimen with a peak rate

7 of $150 \mathrm{~mm} / \mathrm{s}$ (peak strain rate of 0.05 per second) and an identical, quasi-statically loaded

8 specimen and observed little influence of loading rate. The loading rate achieved in this project

9 was four times that reported by Fell et al. Considering the short fundamental period of the

10 specimen $(0.21 \mathrm{sec})$, this loading rate may represent an upper bound for strain rates experienced

11 by braces in a reasonably designed CBF. Compared to the braces used to calibrate the rain-flow-

12 count fracture model, the braces in this program were expected to exhibit a shorter fatigue life

13 due to the slightly larger $b / t$ ratio. However, Fig. 14 to 15 show that the braces survived one

14 more inelastic cycle than the simulated braces. Therefore, although no conclusive statement can

15 be made, Fig. 14 to 15 suggest that the loading rate produced by severe earthquake ground

16 motions do not cause negative effects on the performance of CBFs.

\section{Behavior}

The dynamic response of the specimen was quite different from the response predicted by

19 monotonic loading analysis. While the monotonic analysis in Fig. 3 suggests the likelihood of

20 forming a plastic hinge at mid-span of the beam, no sign of yielding was observed at this location

21 in the shake-table test or in the numerical simulation of the specimen. While Fig. 3 suggests that

22 the tension brace can develop substantial yielding, the braces in the shake-table test and 
1 numerical simulation developed limited tension. The discrepancies are caused by the strong

2 dependency of brace behavior to the loading history and by the limitation of the pushover

3 analysis procedure to account for cyclic loading effects (Krawinkler and Seneviratna 1998).

\section{Drift Capacity}

The CBF frame underwent two and one-half drift cycles between -0.015 and $+0.01 \mathrm{rad}$.

6 before the braces fractured. This drift range is similar to the drift range reported by Uriz (2005)

7 but smaller than what is reported by Lehman et al. (2008) and Roeder et al. (2011). The limited

8 drift capacity may be attributed to the violation of $b / t$ limit by the braces. The $b / t$ ratio of the two

9 braces was 20.4 against the seismically compact limit of 18.5 based on the nominal yield

10 strength $F_{y}=245 \mathrm{MPa}$ and 14.8 based on the measured yield strength $F_{y}=383 \mathrm{MPa}$. In

11 comparison, the HSS braces tested by Lehman et al. (2008) and Roeder et al. (2011) had a b/t

12 ratio of 11.3 against the seismically compact limit of 16.3 based on the nominal yield strength

13 and between 13.0 and 14.0 based on the measured yield strength. The HSS braces tested by Uriz

14 (2005) may have been negatively affected by the thicker gusset plates compared to those

15 recommended by Lehman et al. (2008) that cause larger plastic curvature at the plastic hinge.

\section{Conclusions}

A series of large-scale shake table tests were conducted to examine the dynamic response

18 of CBFs. The tests used a 70\%-scale, single-bay, single-story moment resisting frame specimen

19 with a pair of square HSS braces placed in a chevron arrangement. The braces had a width-to-

20 thickness ratio of 20.4 and member slenderness ratio of 82.5. Because the width-to-thickness

21 ratio was greater than the seismically compact limit of 18.5 , the specimen did not qualify as a 
1 special CBF per the 2005 AISC Seismic Provisions. The measured yield strength of the brace

2 material was $56 \%$ larger than its nominal yield strength. This measured-to-nominal yield strength

3 ratio is similar to what is reported by Lehman et al. (2008) and Roeder et al. (2011) for ASTM

4 A500 Grade B material. The gusset plate connections were designed according to the balanced

5 design proposed by Lehman et al. (2008). The specimen was subjected to a number of

6 unidirectional ground motions with increasing intensity. During the final excitation, both braces

7 experienced buckling, inelastic deformation, and ultimately fracture. Prior to brace fracture, the

8 frame underwent two and one-half drift cycles between -0.015 and +0.01 rad., or a total drift

9 range of $0.025 \mathrm{rad}$. After the brace fractured, the underlying moment frame developed a story

10 drift between -0.018 and +0.028 rad. without any strength loss. After all tests were completed,

11 no discernable damage was observed at the bracing connections. No fracture was observed in the

12 welds between the brace and gusset plate or in the welds connecting the gusset plate to framing

13 elements. Although static pushover analysis predicts plastic hinge formation in the beam due to

14 the force unbalance between the tension and compression braces, the specimen did not form this

15 plastic hinge. Elastic deformation of the beam increased brace contraction and limiting brace

16 extension and thereby, the force unbalance was smaller than expected from the pushover analysis.

17 The rather limited fatigue life of the braces may be attributed to the $b / t$ ratio of the HSS section

18 violating the seismically compact limit. A numerical model was constructed using fiber elements

19 and incorporating fracture that can initiate according to a calibrated rain-flow-count rule. The

20 story drift, story shear, brace elongation, and force distribution recorded from the shake table

21 tests was traced fairly accurately by the numerical model. The model was able to predict the

22 occurrence of brace fracture and subsequent behavior of the frame although the timing of

23 fracture was not captured. 


\section{Acknowledgement}

2 The project presented in this study was funded by the National Research Institute for

3 Earth Science and Disaster Prevention of Japan. Ms. Sachi Furukawa, Mr. Ryo Umehara, and Mr.

4 Xuchuan Lin helped processing the data. Special thanks are extended to the administrative and

5 technical staff at E-Defense, officially named the Hyogo Earthquake Engineering Research

6 Center. Mr. Chui-Hsin Chen and Professor Steve Mahin at the University of California, Berkeley,

7 kindly shared information on their numerical models. The opinions expressed in this paper are

8 those of the authors and do not necessarily reflect the views of the individuals and organizations

9 mentioned above. 


\section{References}

American Institute of Steel Construction, Inc. (AISC). (2005a). Seismic Provisions for Structural Steel Buildings. ANSI/AISC Standard 341-05. AISC, Chicago, Illinois.

American Institute of Steel Construction, Inc. (AISC). (2005b). Specification for Structural Steel Buildings. ANSI/AISC Standard 360-05. AISC, Chicago, Illinois.

Architectural Institute of Japan (AIJ). (2002). Recommendations for Limit State Design of Steel Structures. AIJ, Tokyo, Japan (in Japanese).

Astaneh-Asl, A., Goel, S.C, and Hanson, R.D. (1986). "Earthquake-resistant design of double angle bracing." Engineering Journal, AISC, 23(4), 133-147.

Black, R.G., Wenger, W.A., and Popov, E.P. (1980). "Inelastic buckling of steel struts under cyclic load reversals." Report No. UCB/EERC-80-40, Earthquake Engineering Research Center, University of California, Berkeley, California.

Fell, B.V., Kanvinde, A.M., Deierlein, G.G., and Myers, A.T. (2009), "Experimental investigation of inelastic cyclic buckling and fracture of steel braces," Journal of Structural Engineering, ASCE, 135(1), 19-32.

Fukuta,T., Nishiyama, I., Yamanouchi, H., and Kato, B. (1989). "Seismic performance of steel frames with inverted V braces.” Journal of Structural Engineering, ASCE, 115(8), 20162028.

Gupta, A. and Krawinkler, H. (1999). "Seismic demands for performance evaluation of steel moment resisting frame structures.” Rep. No. 132, the John A. Blume Earthquake 
Engineering Center, Department of Civil and Environmental Engineering, Stanford University, Stanford, CA.

Khatib, I.F., Mahin, S.A., and Pister, K.S. (1988). "Seismic behavior of concentrically braced steel frames." Report UCB/EERC-88/01, Earthquake Engineering Research Center, University of California, Berkeley, CA.

Krawinkler, H. and Seneviratna, P. (1998). "Pros and cons of a pushover analysis for seismic performance evaluation," Engineering Structures, 20(4-6), 452-464.

Lehman, D.E., Roeder, C.W., Herman, .D, Johnson, S., and Kotulka, B. (2008). "Improved seismic performance of gusset plate connections." Journal of Structural Engineering, ASCE, 134(6), 890-901.

Ma, X., Deierlein, G., Eatherton, M., Krawinkler, H., Hajjar, J., Takeuchi, T., Kasai, K., Midorikawa, M., and Hikino, T. (2010). "Large-scale shaking table tests of steel braced frame with controlled rocking and energy dissipating fuses." 9th U.S. National and 10th Canadian Conference on Earthquake Engineering, Paper No. 1681, Toronto, Quebec, Canada, July 25-29, 2010.

McKenna, F. (1997). “Object oriented finite element programming frameworks for analysis, algorithms and parallel computing," Ph.D. Dissertation, University of California, Berkeley, CA.

Nakamura, Y., Uehan, F., and Inoue, H. (1996). "Waveform and its analysis of the 1995 Hyogoken-Nanubu Earthquake II.” JR Earthquake Information No. 23d, UrEDAS R\&D Promotion Department, Railway Technical Research Institute, Tokyo, Japan. 
Nakashima, M. and Wakabayashi, M. (1992). “Analysis and design of steel braces and braced frames in building structures." Chapter in: Stability and Ductility of Steel Structures under Cyclic Loading, Edited by Fukumoto, Y. and Lee, G. CRC Press.

Nakashima, M., Suita, K., Morisako, K., and Maruoka, Y. (1998). “Tests of welded beamcolumn subassemblies. I: Global behavior.” Journal of Structural Engineering, ASCE, 124(11), 1236-1244.

National Institute of Standards and Technology (NIST). (2010). Evaluation of the FEMA P-695 Methodology for Quantification of Building Seismic Performance Factors. GCR 10-9178. Prepared by the NEHRP Consultants Joint Venture for NIST, Gaithersburg, MD.

Popov, E.P., Takanashi, K., and Roeder, C.W. (1976). "Structural steel bracing systems: behavior under cyclic loading." Report No. EERC 76-17, Earthquake Engineering Research Center, University of California, Berkeley, California.

Roeder, C.W. and Lehman, D.E. (2009). "Performance and behavior of gusset plate connections." North American Steel Construction Conference, Phoenix, Arizona, April 1-4, 2009.

Roeder, C.W., Lehman, D.E., Clark, K., Powell, J., Yoo J.-H., Tsai, K.-C., Lin, C.-H., and Wei, C.-Y. (2011). "Influence of gusset plate connections and braces on the seismic performance of X-braced frames.” Earthquake Engineering and Structural Dynamics, 40, $355-374$.

Roeder, C.W., Lumpkin, E.J., Lehman, D.E. (2011). “A balanced design procedure for special concentrically braced frame connections." Journal of Constructional Steel Research, 67, 1760-1772. 
Shibata, M. and Wakabayashi, M. (1963). "Experimental study on the hysteretic behavior of Ktype braced frame subjected to repeated load.” Transactions, Architectural Institute of Japan, 326, 10-16.

Takeuchi, T., Kasai, K., Midorikawa, M., Matsuoka, Y., Asakawa, T., Kubodera, I., Kurokawa, Y., Kishiki, S., and Ando, H. (2008). "Shaking table test using E-Defense multipurpose test bed." 14th World Conference on Earthquake Engineering, Beijing, China, October 12-17, 2008.

Tremblay, R. and Robert, N. (2001). "Seismic performance of low- and medium-rise chevron braced steel frames.” Canadian Journal of Civil Engineering, 28, 699-714.

Tremblay, R. (2001). "Seismic behavior and design of concentrically braced steel frames." Engineering Journal, American Institute of Steel Construction, 38(3), Chicago, Illinois.

Tremblay, R. (2002). “Inelastic seismic response of steel bracing members.” Journal of Constructional Steel Research, 58, 665-701.

Uriz, P. (2005). “Towards earthquake resistant design of concentrically braced steel structures." Ph.D. Dissertation, Department of Civil and Environmental Engineering, University of California, Berkeley, California.

Uriz, P., Filippou, F.C., and Mahin, S.A. (2008). "Model for cyclic inelastic buckling of steel braces.” Journal of Structural Engineering, ASCE, 134(4), 619-628. 
Yamanouchi, H., Midorikawa, M., Nishiyama, I., and Watabe, M. (1989). "Seismic behavior of full-scale concentrically braced steel building structure.” Journal of Structural Engineering, ASCE, 115(8), 1917-1929. 


\section{List of Tables}

Table 1 Material properties

Table 2 Scaling rule 


\section{List of Figures}

Fig. 1 Test specimen and out-of-plane bracing points. (Units in $\mathrm{mm}$ ).

Fig. 2 Details of bracing connections

Fig. 3 Monotonic loading response of specimen

Fig. 4 Specimen and test-bed system

Fig. 5 Ground motion: (a) JR Takatori EW acceleration history; and (b) response spectra for $h$ $=0.02$.

Fig. 6 Determination of brace forces: (a) strain gauge scheme; and (b) assumed equilibrium.

Fig. 7 Frame response from: (a) 28\%; (b) $42 \%$; and (c) $70 \%$ motion.

Fig. 8 Axial response of East brace from: (a) 28\%; (b) 42\%; and (c) $70 \%$ motion.

Fig. 9 End rotation of East brace from: (a) 28\%; (b) 42\%; and (c) $70 \%$ motion.

Fig. 10 Specimen after 70\% motion: (a) fractured West brace; (b) gusset plate at the East column base; (c) gusset plate connecting braces to beam.

Fig. 11 Brace elongation and beam deflection: (a) brace elongation; and (b) vertical displacement (upward positive) of beam.

Fig. 12 Numerical Model. (Unit in $\mathrm{mm}$ ).

Fig. 13 Validation of brace hysteresis and ccalibrated fracture model using test by Fell et al. (2009). 
Fig. 14 Simulated versus experimental East brace response for (a) 42\%; and (b) $70 \%$ motion.

Fig. 15 Simulated versus experimental frame response for (a) 42\%; and (b) $70 \%$ motion. 
Table 1 Material properties

\begin{tabular}{ccccc}
\hline Material & Designation & $\begin{array}{c}F_{y} \\
(\mathrm{MPa})\end{array}$ & $\begin{array}{c}F_{u} \\
(\mathrm{MPa})\end{array}$ & $\begin{array}{c}\text { Elongation } \\
(\%)\end{array}$ \\
\hline Brace & STKR400 & 383 & 452 & 36 \\
Beam flange $(9 \mathrm{~mm})$ & SN400B & 327 & 456 & 27 \\
Beam web $(6 \mathrm{~mm})$ & SN400B & 376 & 472 & 29 \\
Column & BCR295 & 434 & 518 & 19 \\
Gusset plate $(4.5 \mathrm{~mm})$ & SS400 & 204 & 291 & 54 \\
\hline
\end{tabular}


Table 2 Scaling rule

\begin{tabular}{ccc}
\hline Parameters & \multicolumn{2}{l}{ Scaling Factor } \\
Length & $\lambda$ & 0.7 \\
Mass & $\lambda$ & 0.7 \\
Acceleration & $\lambda$ & 0.7 \\
Time & 1 & 1 \\
Force & $\lambda^{2}$ & 0.5 \\
Velocity & $\lambda$ & 0.7 \\
Stress & 1 & 1 \\
\hline
\end{tabular}




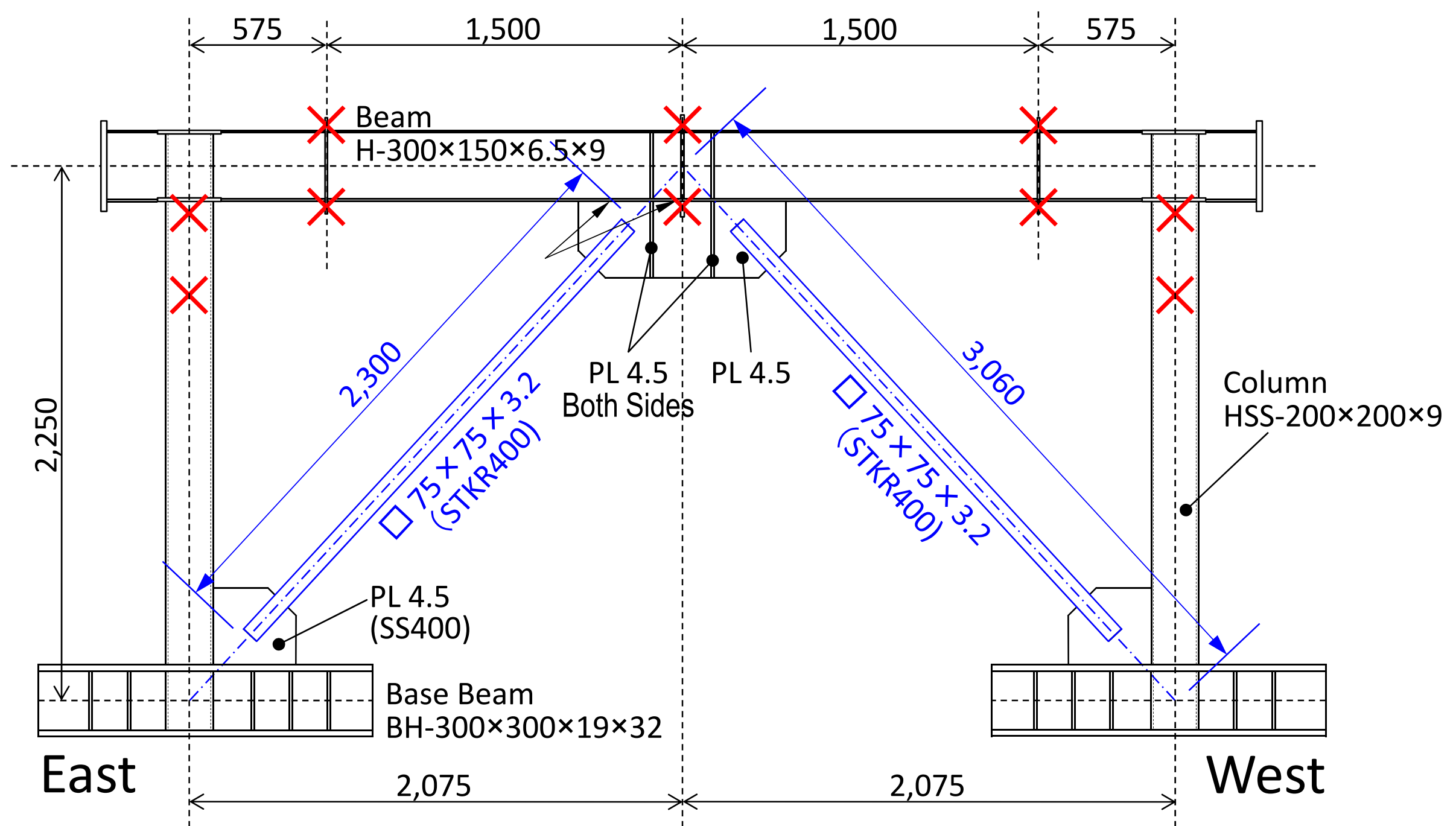




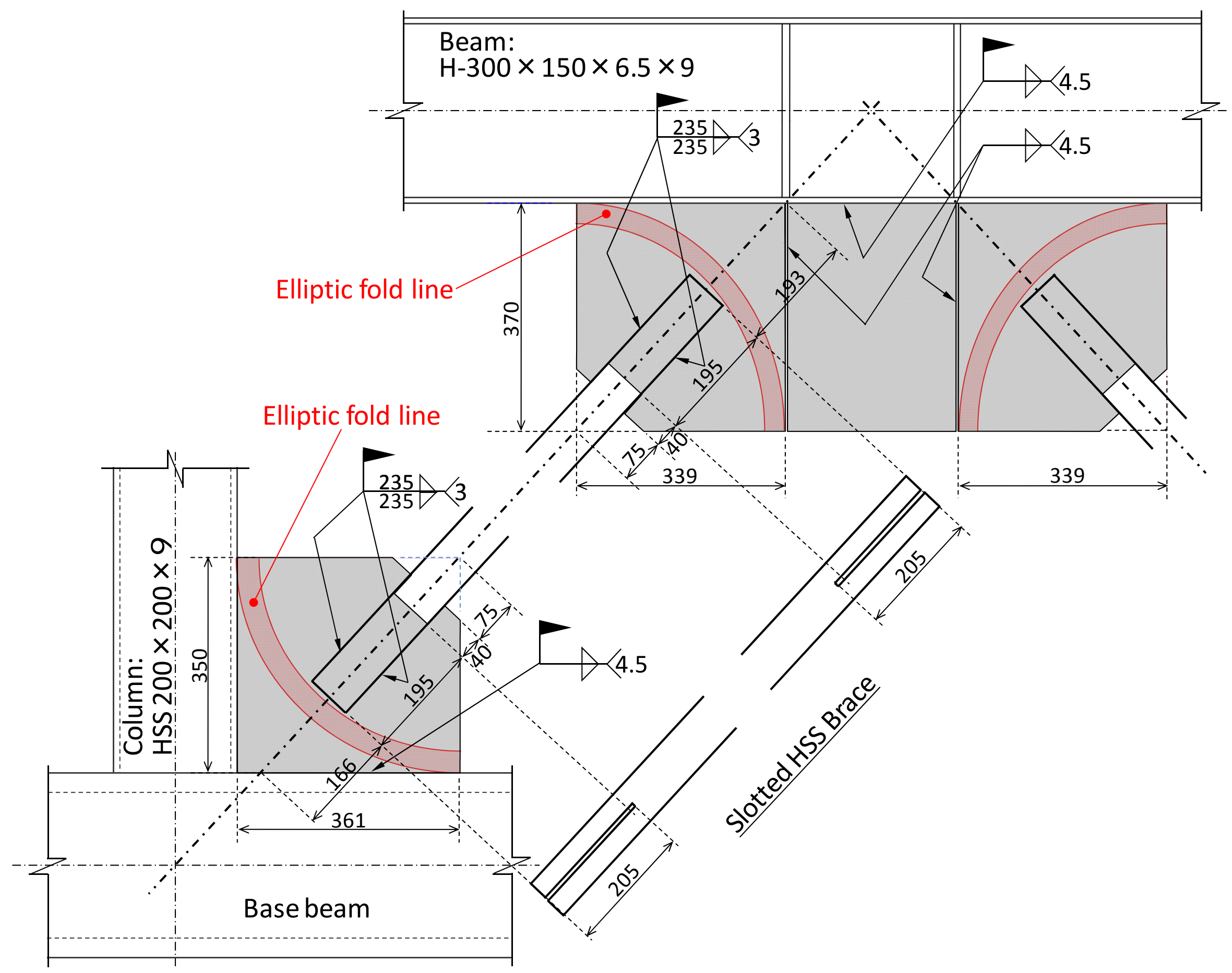




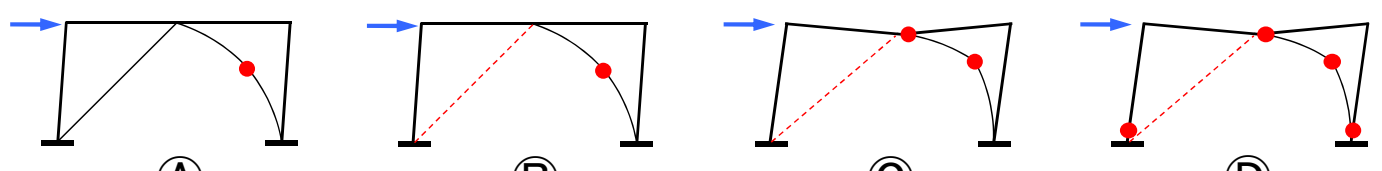
(A)
(B)
(C)
(D)
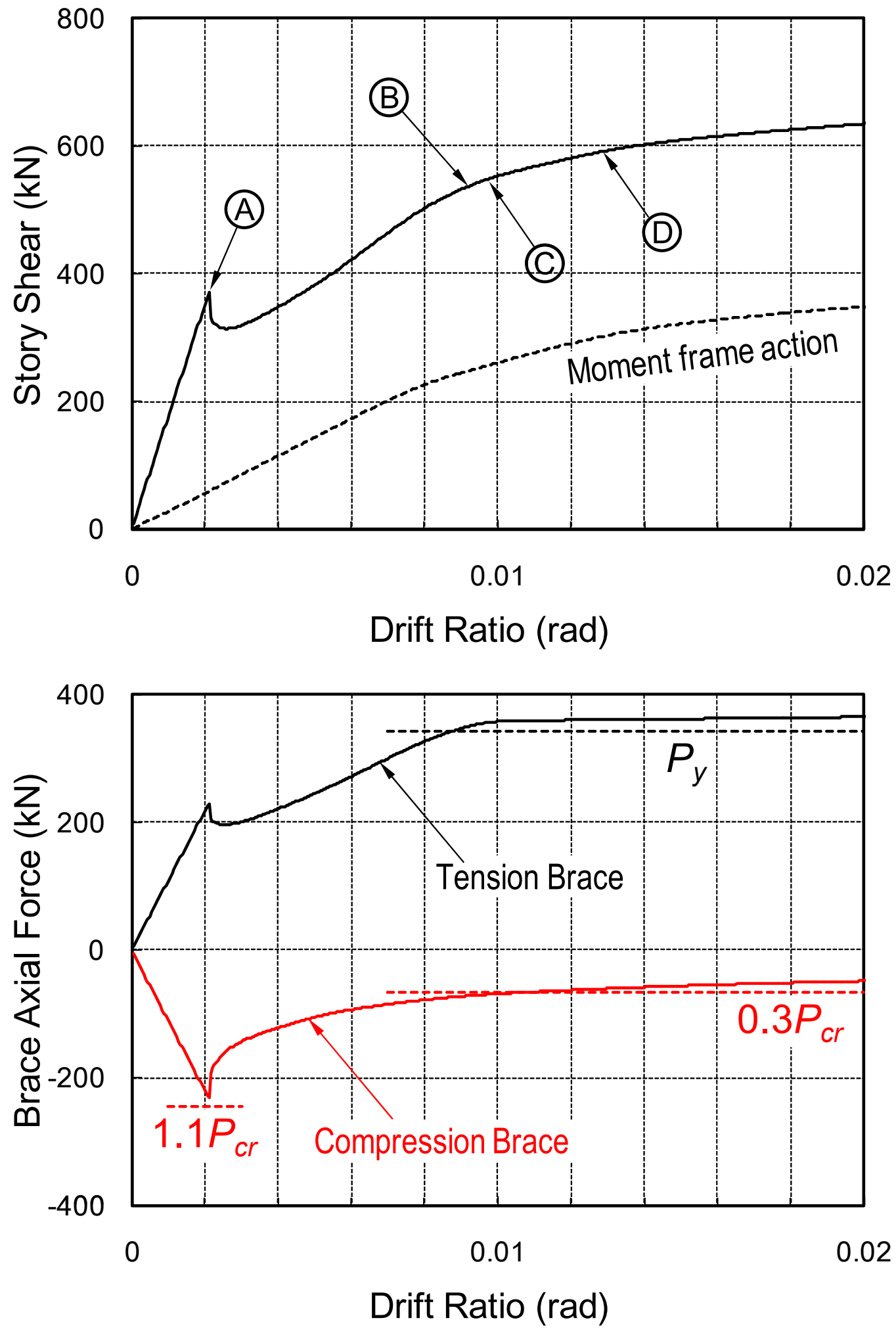


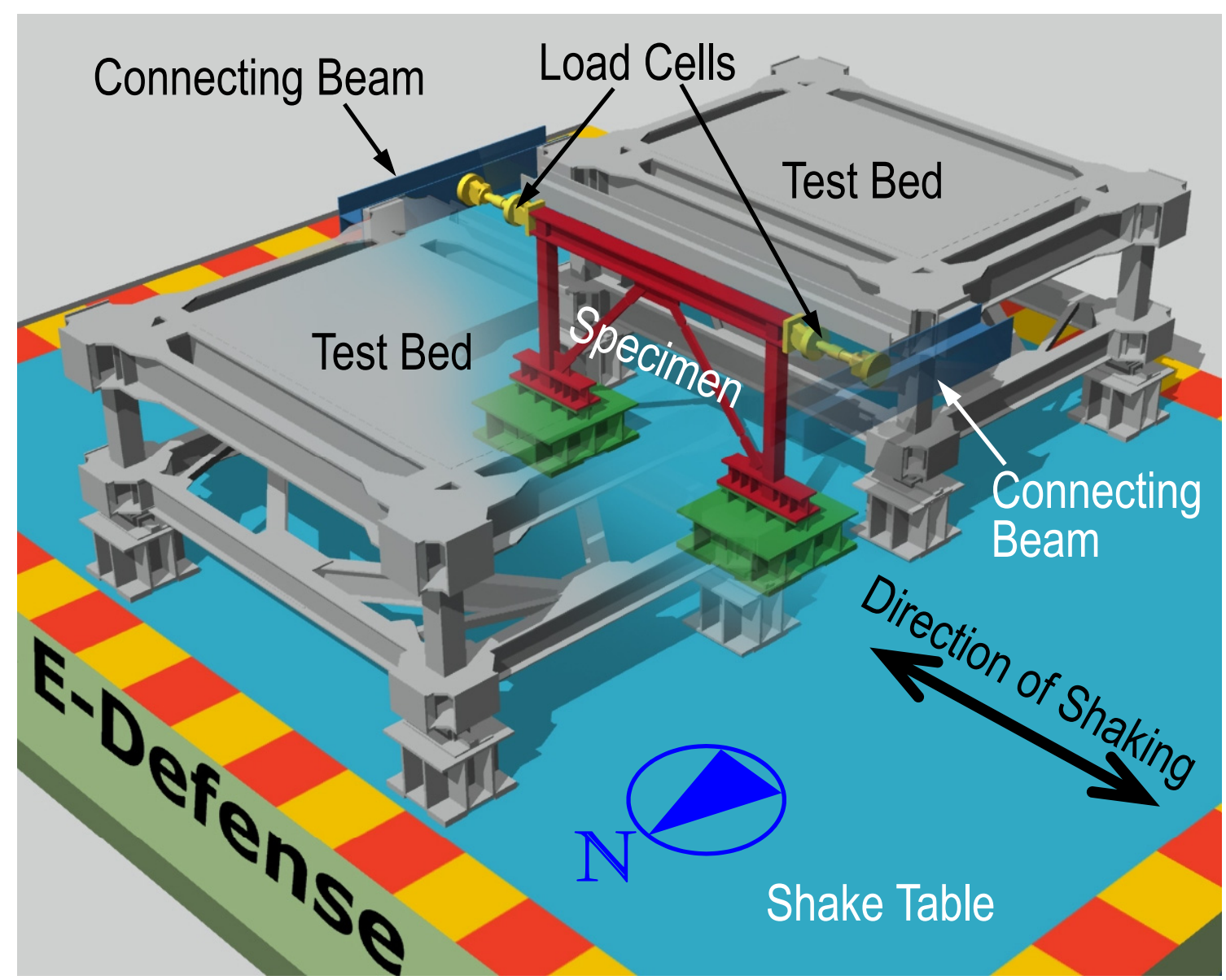



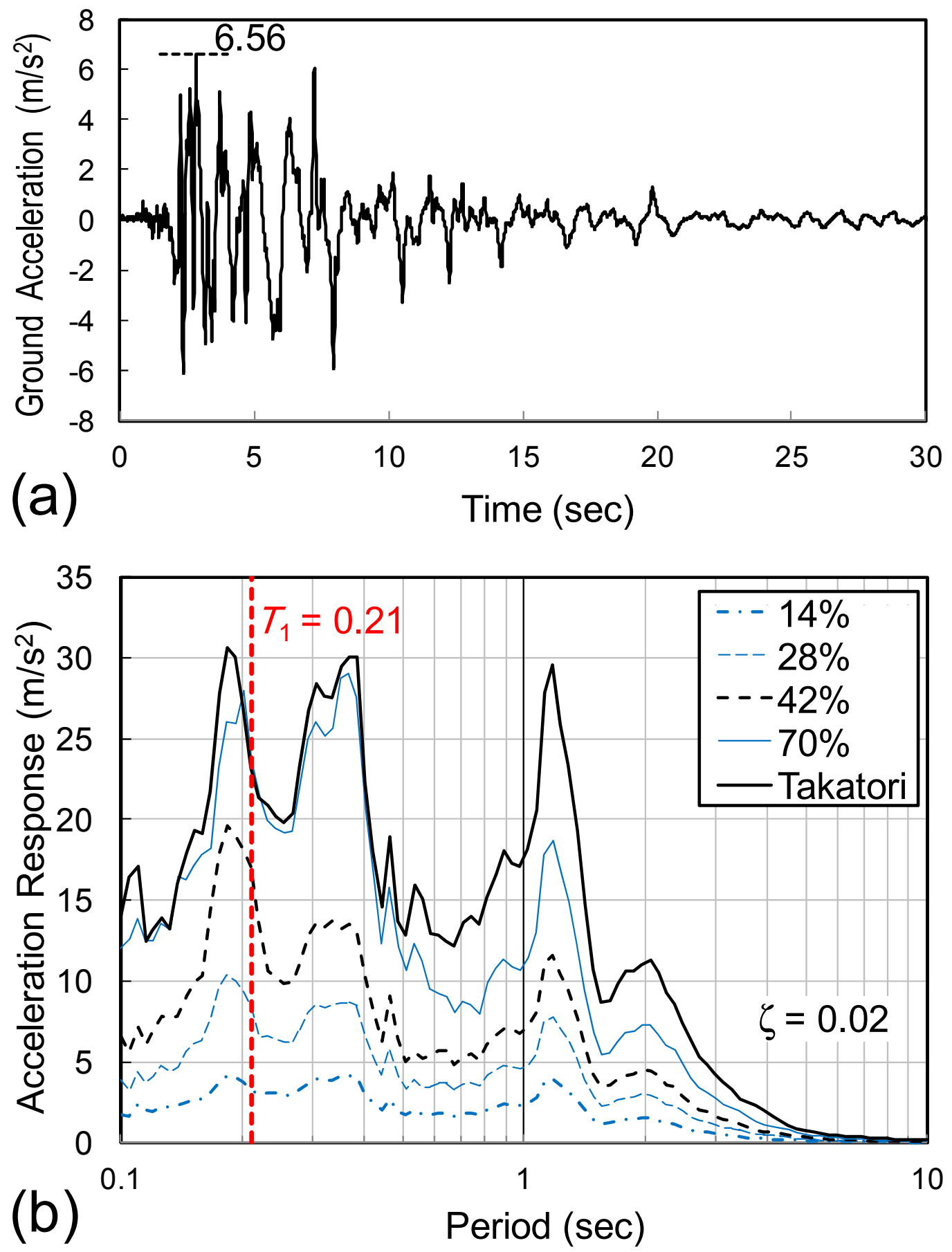


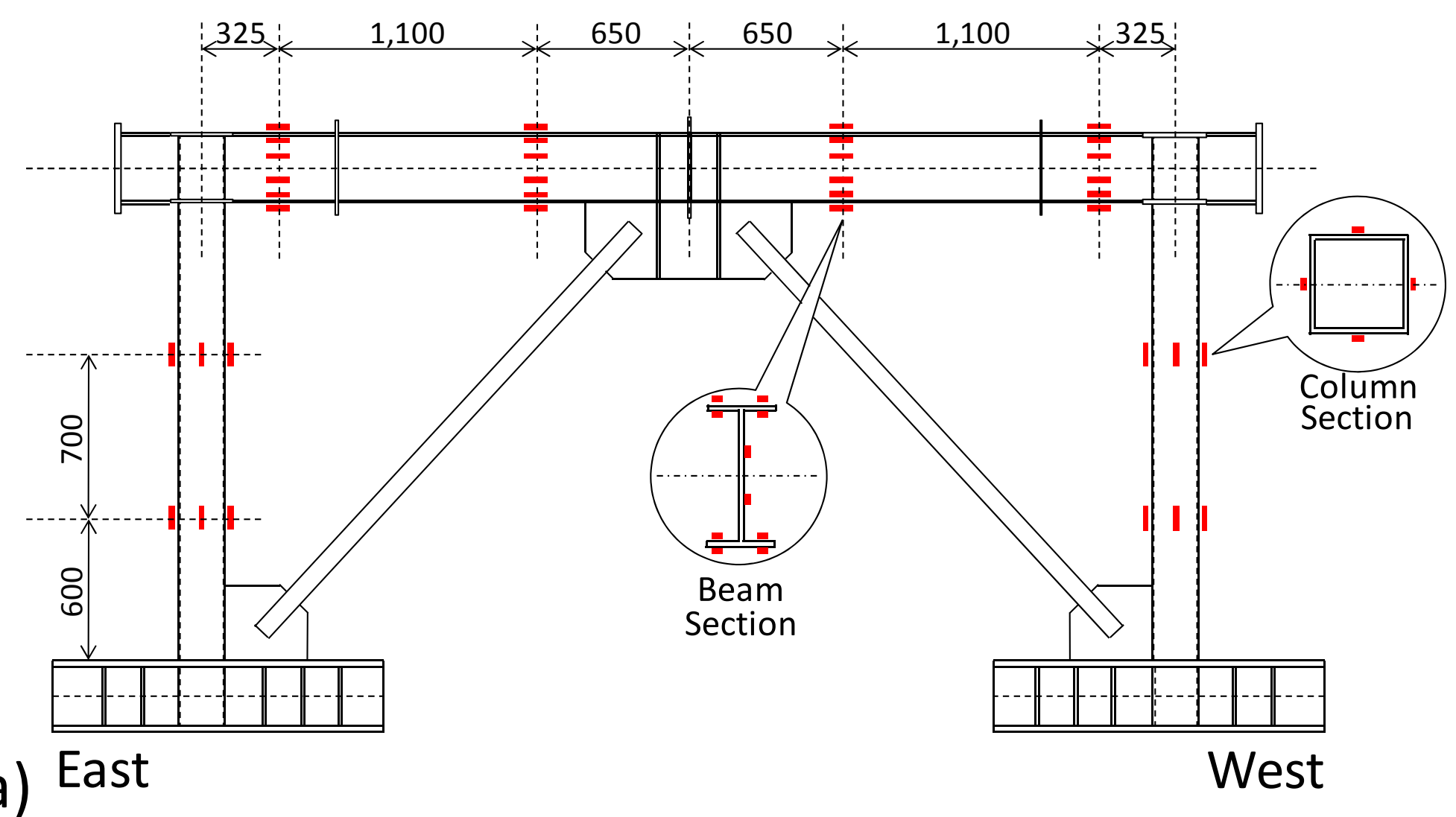

(b)

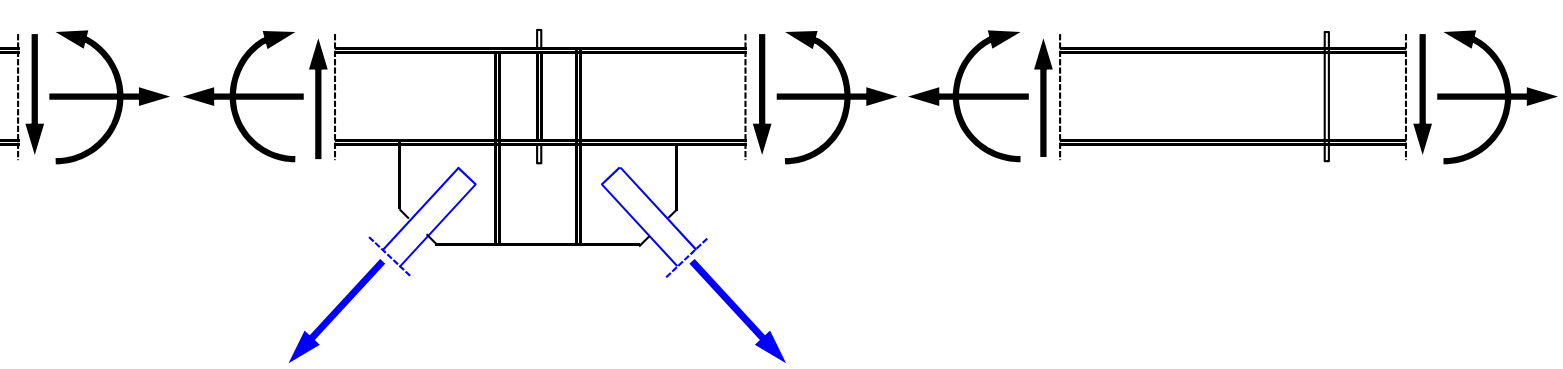




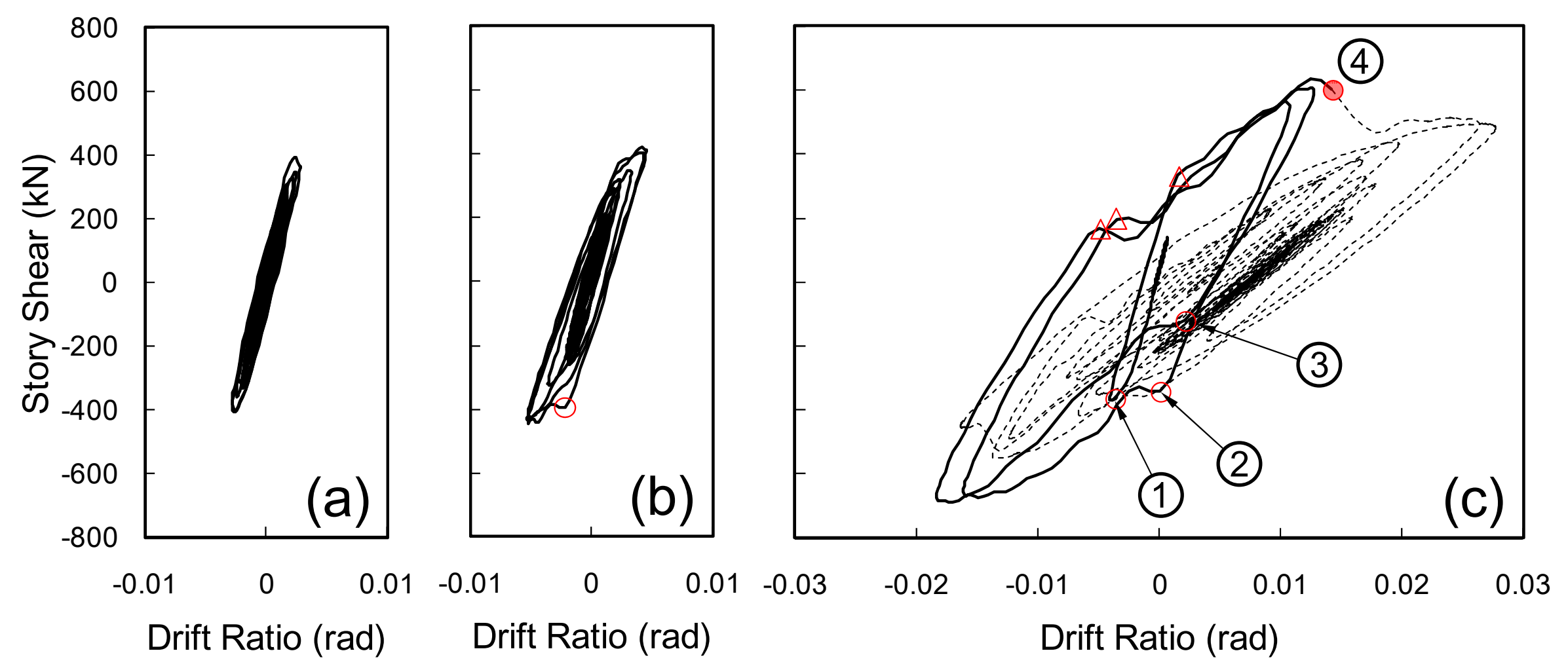



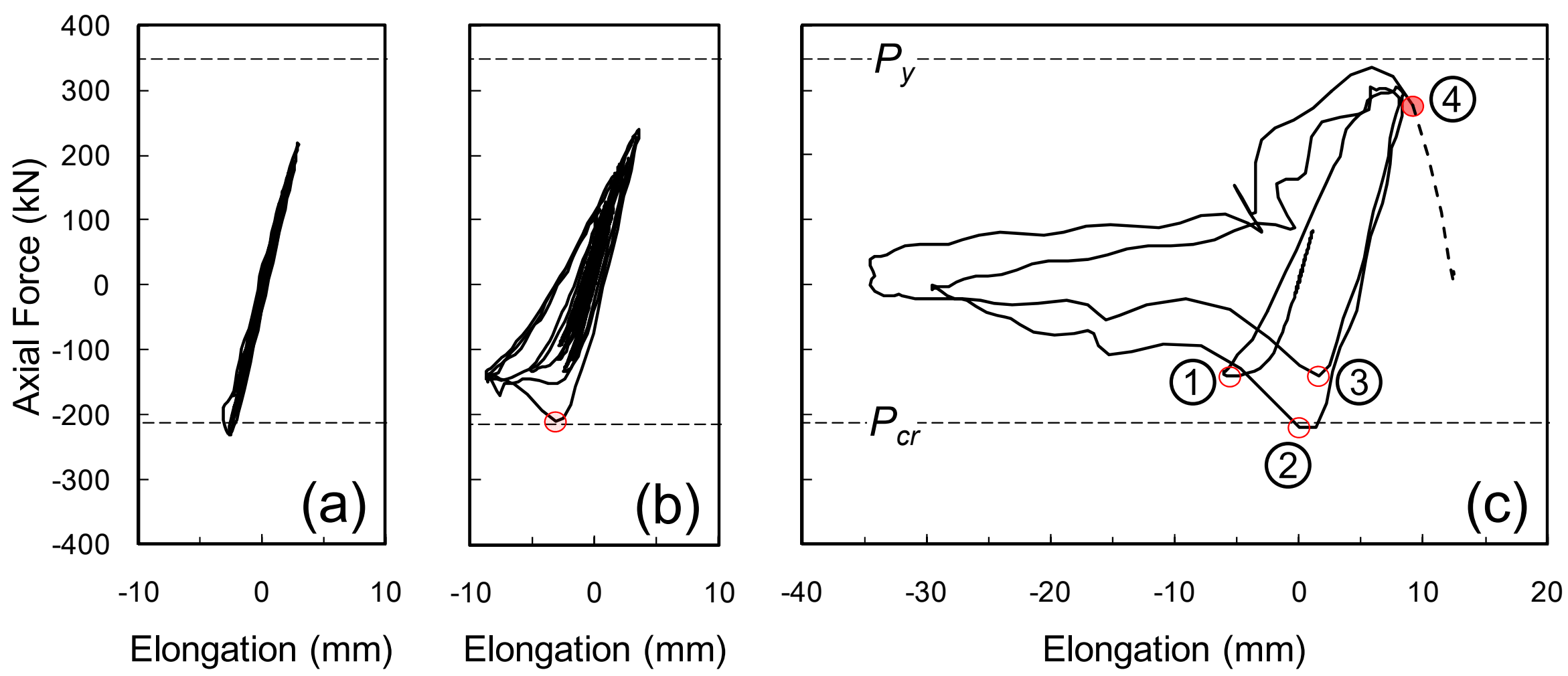

Elongation $(\mathrm{mm}) \quad$ Elongation $(\mathrm{mm})$

Elongation ( $\mathrm{mm}$ ) 

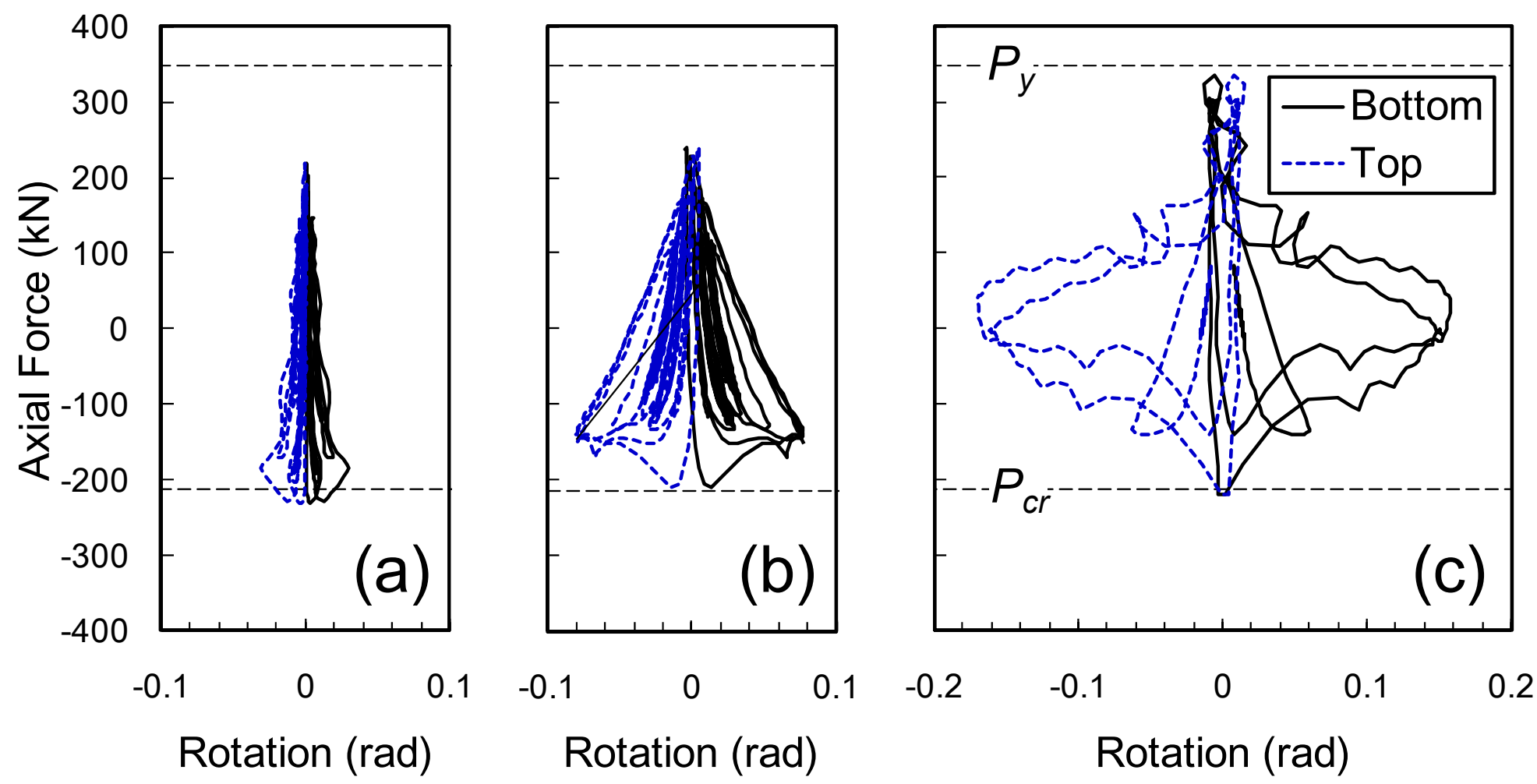

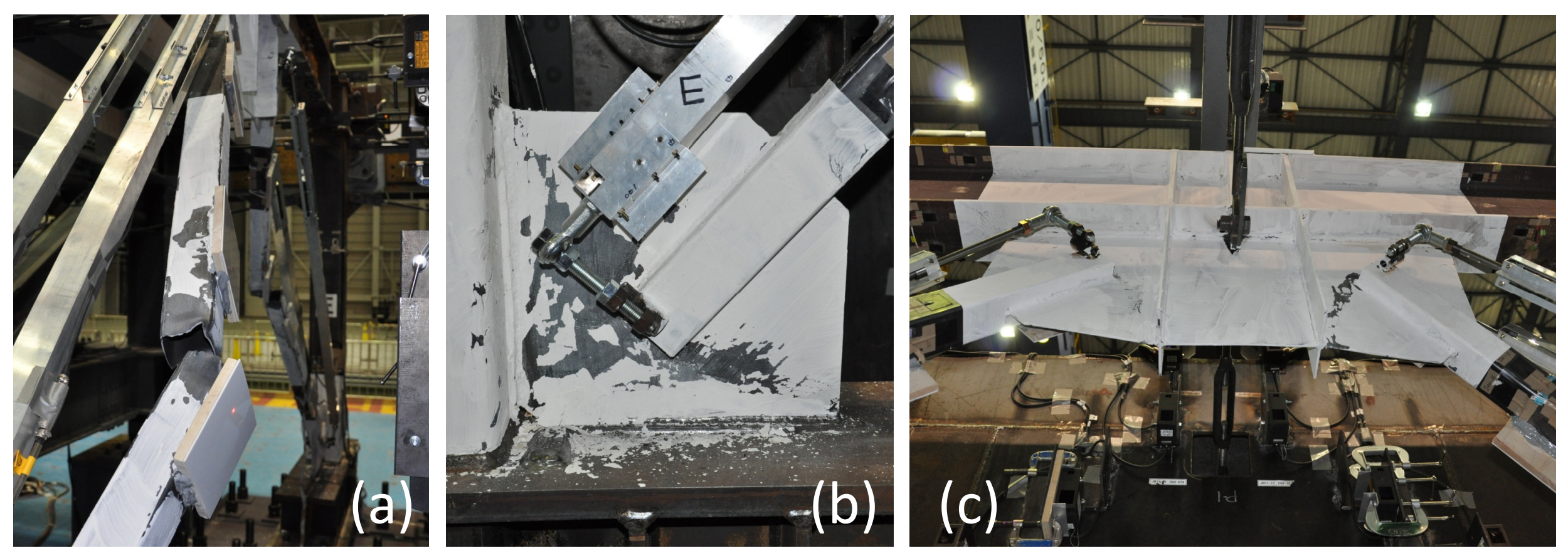

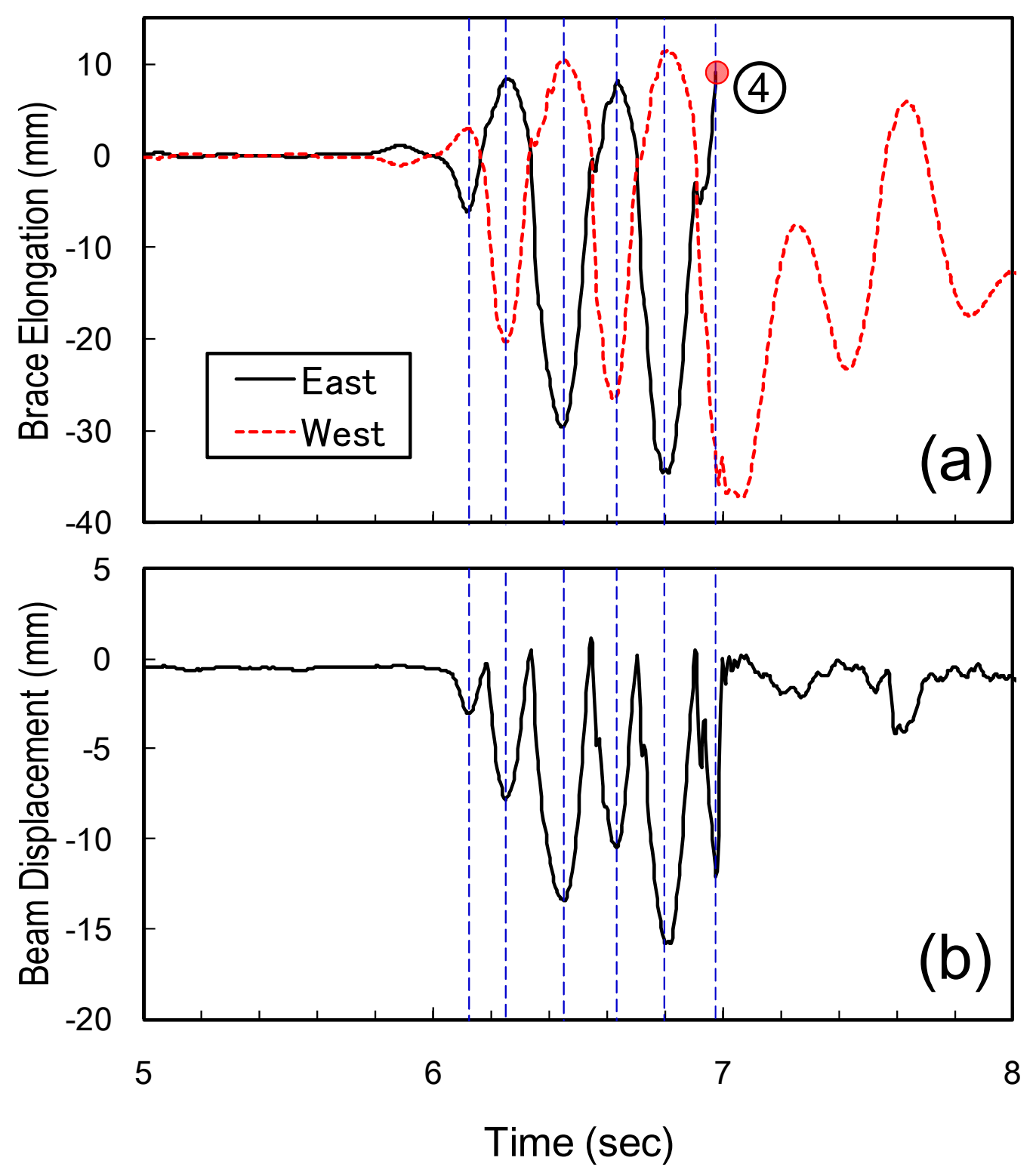


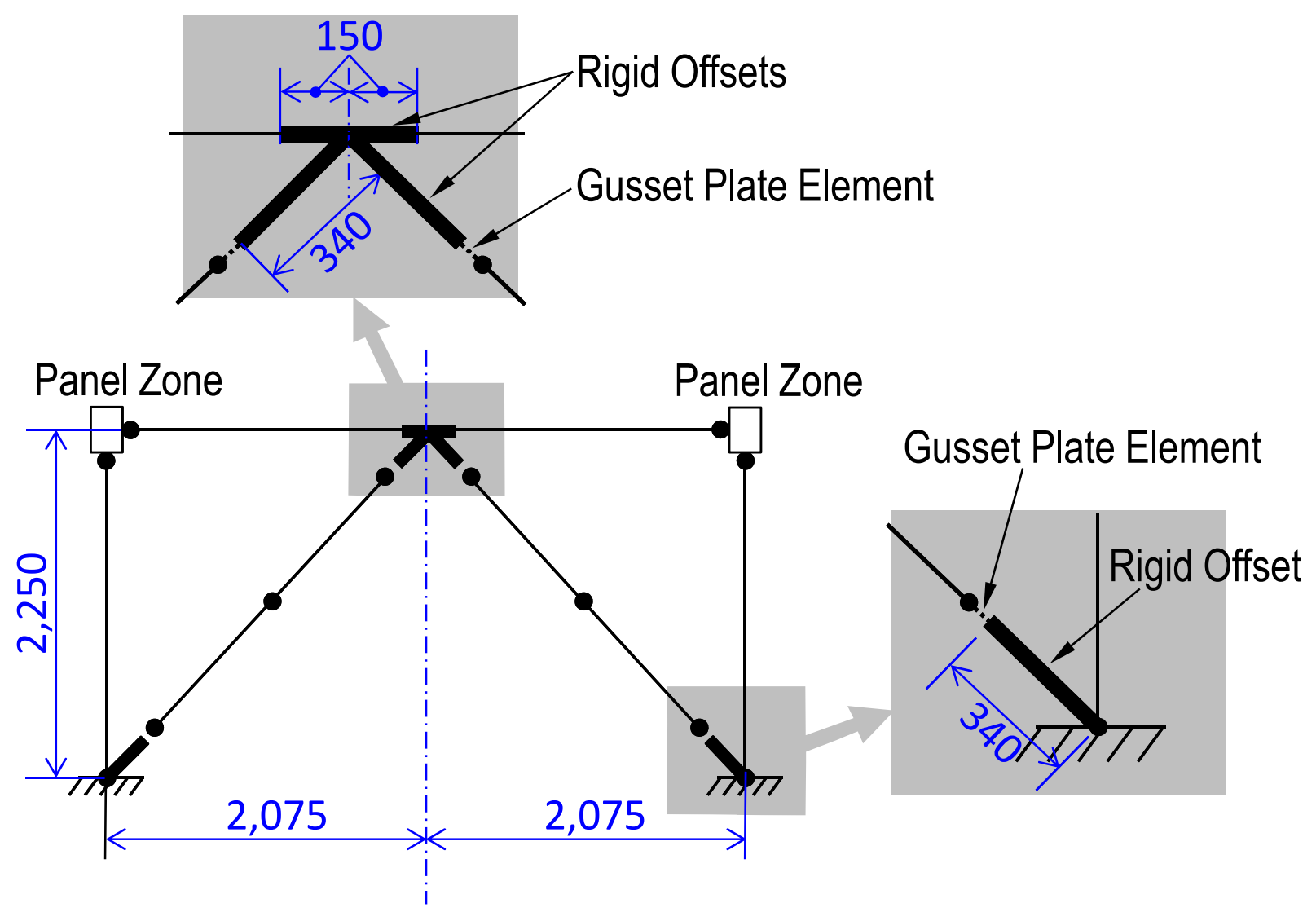




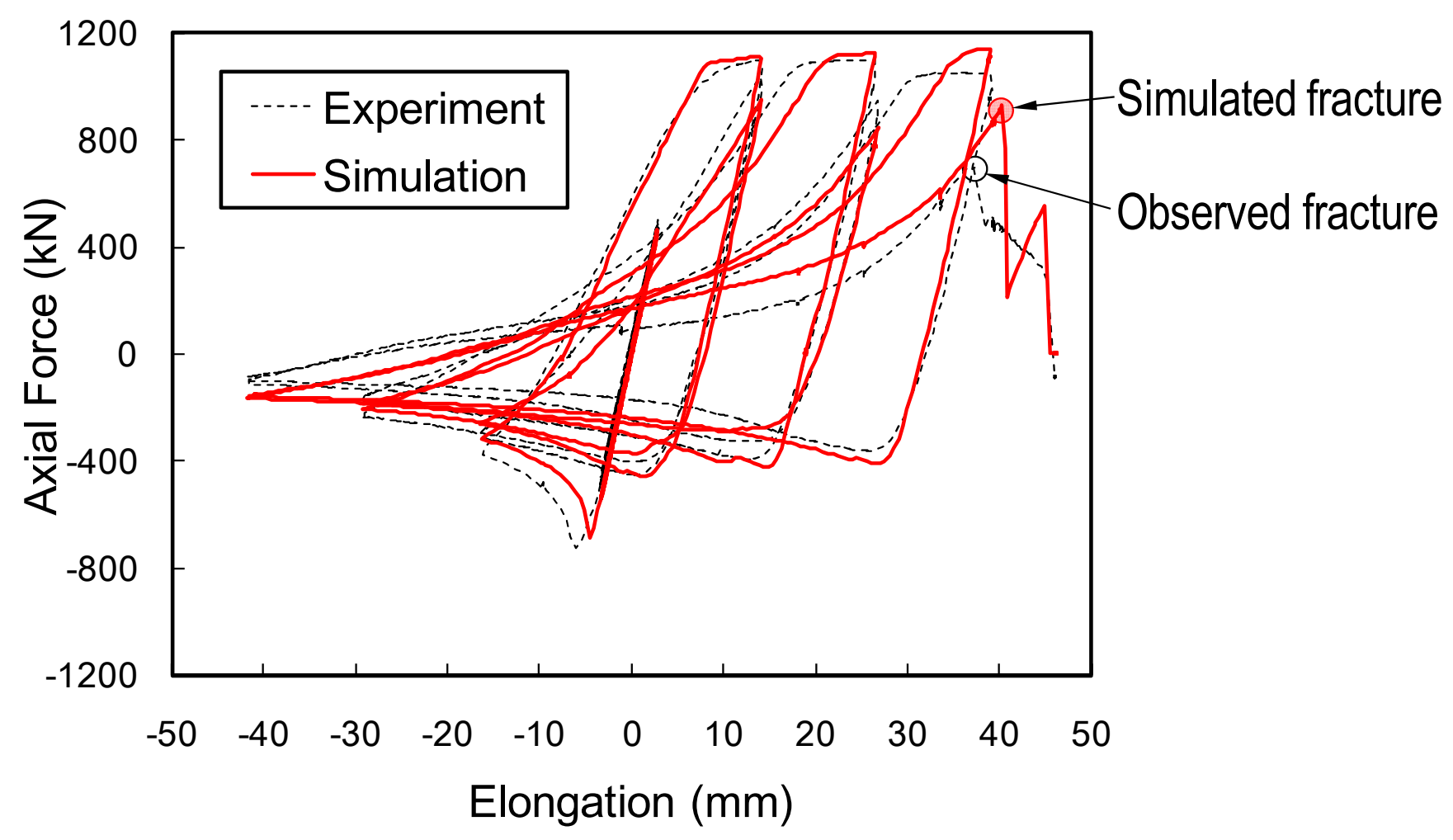



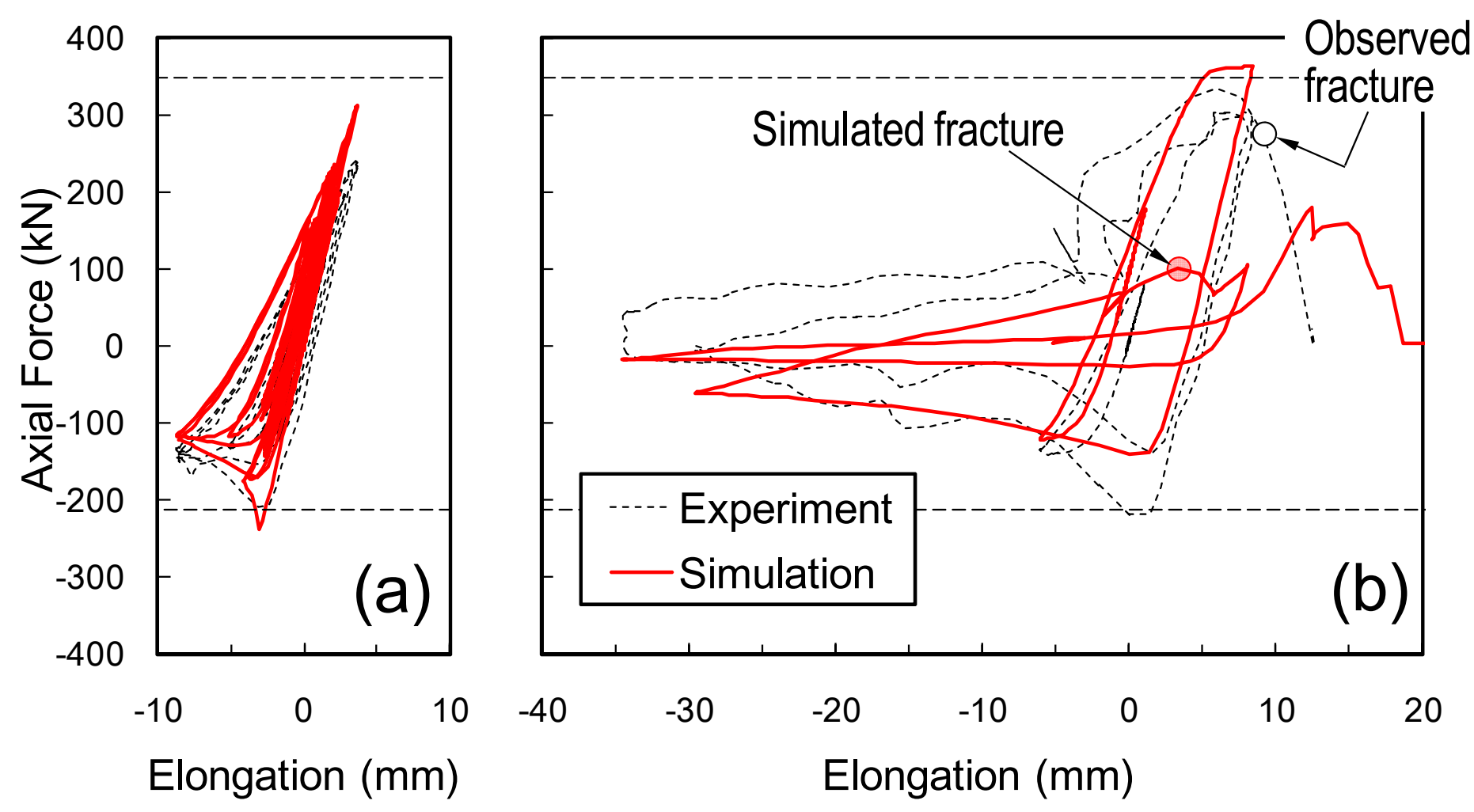


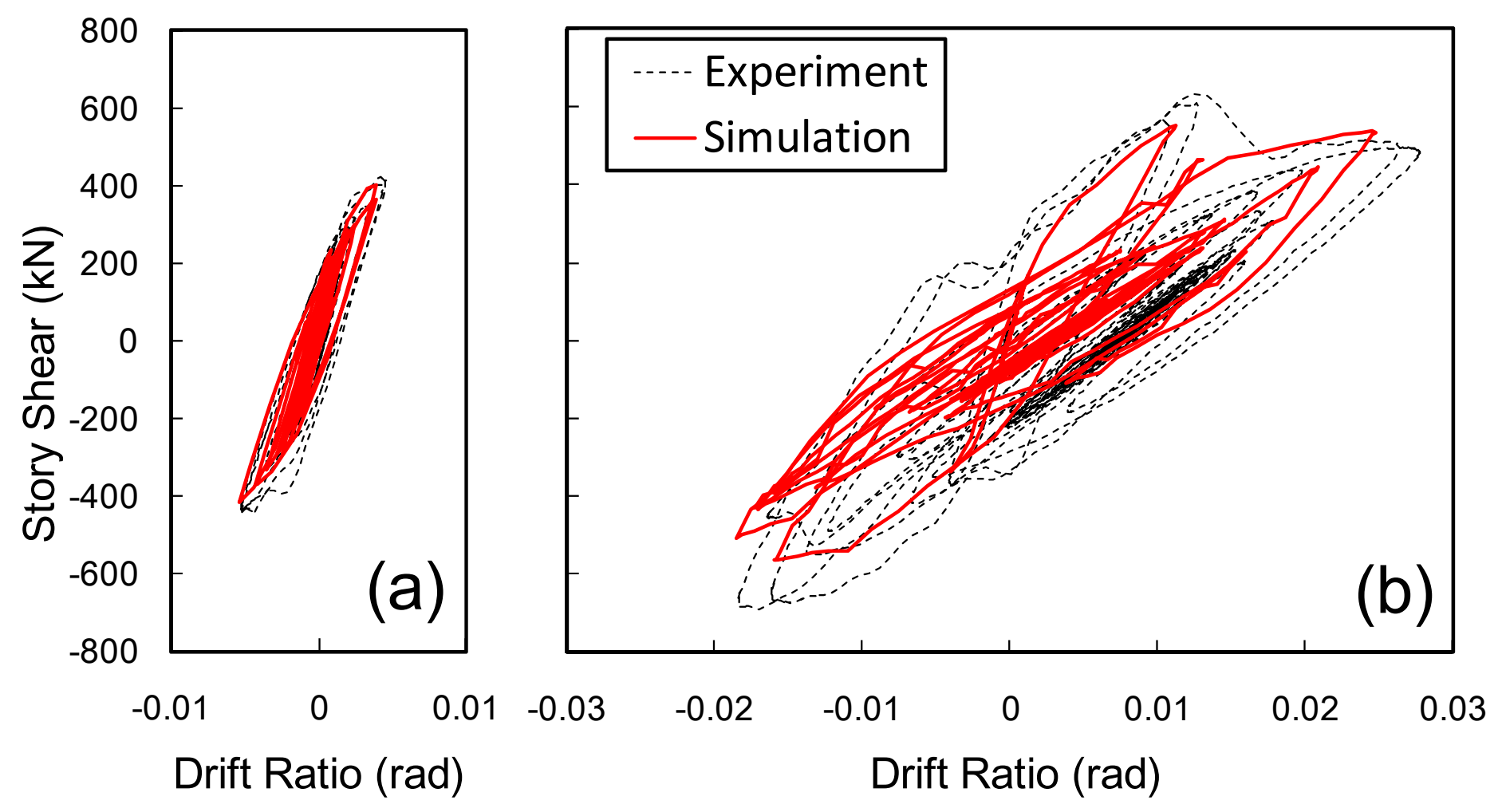

